Supplement of Biogeosciences, 12, 3953-3971, 2015

http://www.biogeosciences.net/12/3953/2015/

doi:10.5194/bg-12-3953-2015-supplement

(C) Author(s) 2015. CC Attribution 3.0 License.

(c) (1)

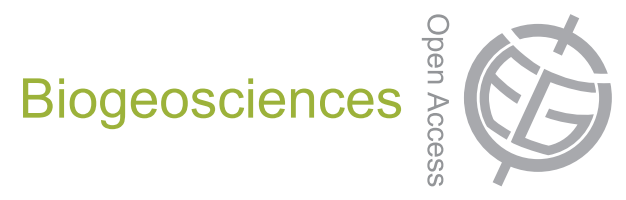

Supplement of

\title{
Carbon export and transfer to depth across the Southern Ocean Great Calcite Belt
}

\section{S. Z. Rosengard et al.}

Correspondence to: S. Z. Rosengard (srosengard@whoi.edu); P. J. Lam (pjlam@ucsc.edu)

The copyright of individual parts of the supplement might differ from the CC-BY 3.0 licence. 


\section{Supplement Contents}

This supplement contains, in the following order:

Table S1: tabulated ${ }^{234}$ Th activity, ${ }^{234} \mathrm{U}$ activity and ${ }^{234} \mathrm{Th}$ flux profiles

Table S2: tabulated ${ }^{234} \mathrm{Th}$ and POC fluxes and POC: ${ }^{234} \mathrm{Th}$ ratios at $\mathrm{z}_{\mathrm{Th} / \mathrm{U}}$

Figure S1. Plotted profiles of POC: ${ }^{234} \mathrm{Th}, \mathrm{PIC}:{ }^{234} \mathrm{Th}$ and BSi: ${ }^{234} \mathrm{Th}$ above $400 \mathrm{~m}$

Figure S2. Euphotic zone diatom or coccolithophore abundance as a function of [BSi] or [PIC], respectively

Figure S3: The natural $\log$ ratio of [PIC] to [BSi] as a function of the natural log ratio of total euphotic zone coccolithophore to diatom abundances

Figure S4: Percentage of total cell counts that are diatoms at $\mathrm{Z}_{\mathrm{PAR}}$ as a function of the insitu pump size fractionation of [POC] at ZPAR

Supplementary Methods: pertaining to data from Figures S2-S4.

Supplementary References 
Table S1 ${ }^{234}$ Th activity and flux profiles estimated at 27 stations along cruises GB1 and GB2. Fluxes were estimated by measuring total seawater ${ }^{234} \mathrm{Th}$ activity deficits relative to total seawater ${ }^{238} \mathrm{U}$ activity, as described in Sect. $2.4 .{ }^{234} \mathrm{Th}$ flux errors are propagated from ${ }^{234} \mathrm{Th}$ activity errors.

\begin{tabular}{|c|c|c|c|c|c|c|c|}
\hline Cruise & Station & Depth & $\begin{array}{l}{ }^{234} \mathrm{Th} \\
\text { Activity }\end{array}$ & $\begin{array}{l}{ }^{234} \text { Th Activity } \\
\text { Error }\end{array}$ & $\begin{array}{l}{ }^{238} \mathrm{U} \\
\text { Activity }\end{array}$ & ${ }^{234}$ Th Flux & $\begin{array}{l}{ }^{234} \text { Th Flux } \\
\text { Error }\end{array}$ \\
\hline- & - & $m$ & $\operatorname{dpm} L^{-1}$ & $d p m L^{-1}$ & $d p m L^{-1}$ & $d p m m^{-2} d^{-1}$ & $d p m m^{-2} d^{-1}$ \\
\hline GB1 & 6 & 13.6 & 1.04 & 0.02 & 2.36 & 681 & 27 \\
\hline GB1 & 6 & 22.3 & 1.28 & 0.05 & 2.36 & 924 & 31 \\
\hline GB1 & 6 & 29.2 & 1.12 & 0.03 & 2.36 & 1,243 & 34 \\
\hline GB1 & 6 & 40.2 & 1.23 & 0.03 & 2.36 & 1,503 & 37 \\
\hline GB1 & 6 & 45.2 & 1.29 & 0.06 & 2.36 & 1,702 & 39 \\
\hline GB1 & 6 & 53.1 & 1.53 & 0.04 & 2.36 & 2,096 & 48 \\
\hline GB1 & 6 & 78 & 1.86 & 0.12 & 2.36 & 2,437 & 100 \\
\hline GB1 & 6 & 100.6 & 1.90 & 0.05 & 2.36 & 2,684 & 106 \\
\hline GB1 & 6 & 115 & 2.08 & 0.10 & 2.36 & 2,804 & 116 \\
\hline GB1 & 6 & 130 & 2.15 & 0.05 & 2.36 & 2,911 & 121 \\
\hline GB1 & 6 & 150.3 & 2.09 & 0.07 & 2.36 & 3,182 & 145 \\
\hline GB1 & 6 & 200 & 2.04 & 0.18 & 2.37 & 3,419 & 195 \\
\hline GB1 & 16 & 11.1 & 0.99 & 0.02 & 2.35 & 548 & 20 \\
\hline GB1 & 16 & 17.07 & 1.10 & 0.02 & 2.35 & 762 & 22 \\
\hline GB1 & 16 & 23.04 & 0.94 & 0.02 & 2.35 & 1,107 & 25 \\
\hline GB1 & 16 & 34.2 & 1.61 & 0.04 & 2.35 & 1,311 & 30 \\
\hline GB1 & 16 & 42.2 & 1.61 & 0.05 & 2.36 & 1,611 & 42 \\
\hline GB1 & 16 & 62.3 & 1.97 & 0.05 & 2.36 & 1,933 & 71 \\
\hline GB1 & 16 & 100.17 & 2.06 & 0.05 & 2.36 & 2,277 & 105 \\
\hline GB1 & 16 & 140.8 & 2.18 & 0.06 & 2.37 & 2,487 & 139 \\
\hline GB1 & 16 & 180.1 & 2.24 & 0.08 & 2.37 & 2,636 & 178 \\
\hline GB1 & 16 & 220.5 & 2.21 & 0.21 & 2.37 & 2,819 & 308 \\
\hline GB1 & 16 & 260.7 & 2.37 & 0.13 & 2.37 & 2,810 & 394 \\
\hline GB1 & 16 & 340.3 & 2.16 & 0.08 & 2.37 & 3,040 & 409 \\
\hline GB1 & 25 & 10.3 & 1.70 & 0.05 & 2.45 & 283 & 26 \\
\hline GB1 & 25 & 16.1 & 1.95 & 0.06 & 2.45 & 380 & 30 \\
\hline GB1 & 25 & 23.8 & 1.91 & 0.03 & 2.45 & 525 & 34 \\
\hline GB1 & 25 & 34.5 & 2.14 & 0.05 & 2.47 & 611 & 38 \\
\hline GB1 & 25 & 41.7 & 2.07 & 0.07 & 2.47 & 773 & 51 \\
\hline GB1 & 25 & 80 & 2.42 & 0.03 & 2.48 & 941 & 74 \\
\hline GB1 & 25 & 115 & 2.46 & 0.04 & 2.45 & 937 & 91 \\
\hline GB1 & 25 & 140.5 & 2.38 & 0.05 & 2.43 & 975 & 103 \\
\hline GB1 & 25 & 165.2 & 2.32 & 0.07 & 2.44 & 1,074 & 125 \\
\hline GB1 & 25 & 200.2 & 2.44 & 0.04 & 2.42 & 1,029 & 177 \\
\hline
\end{tabular}




\begin{tabular}{|c|c|c|c|c|c|c|c|}
\hline GB1 & 25 & 300 & 2.36 & 0.03 & 2.38 & 1,051 & 195 \\
\hline GB1 & 32 & 12.15 & 1.96 & 0.08 & 2.48 & 229 & 41 \\
\hline GB1 & 32 & 18 & 1.96 & 0.06 & 2.48 & 327 & 44 \\
\hline GB1 & 32 & 25.25 & 2.00 & 0.07 & 2.49 & 475 & 51 \\
\hline GB1 & 32 & 39.2 & 2.02 & 0.10 & 2.49 & 614 & 61 \\
\hline GB1 & 32 & 46 & 2.05 & 0.19 & 2.49 & 808 & 104 \\
\hline GB1 & 32 & 69.67 & 1.83 & 0.04 & 2.47 & 1,304 & 116 \\
\hline GB1 & 32 & 100.2 & 2.33 & 0.03 & 2.48 & 1,435 & 127 \\
\hline GB1 & 32 & 130.5 & 2.38 & 0.03 & 2.47 & 1,520 & 141 \\
\hline GB1 & 32 & 171 & 2.41 & 0.09 & 2.46 & 1,581 & 186 \\
\hline GB1 & 32 & 210 & 2.43 & 0.03 & 2.46 & 1,612 & 198 \\
\hline GB1 & 32 & 251 & 2.29 & 0.11 & 2.45 & 1,818 & 250 \\
\hline GB1 & 32 & 300.8 & 2.52 & 0.03 & 2.44 & 1,761 & 253 \\
\hline GB1 & 38 & 20.4 & 2.36 & 0.08 & 2.52 & 127 & 72 \\
\hline GB1 & 38 & 32.2 & 2.17 & 0.03 & 2.52 & 247 & 74 \\
\hline GB1 & 38 & 44.2 & 2.20 & 0.04 & 2.52 & 418 & 83 \\
\hline GB1 & 38 & 69 & 2.28 & 0.10 & 2.53 & 550 & 102 \\
\hline GB1 & 38 & 81 & 2.27 & 0.08 & 2.54 & 638 & 107 \\
\hline GB1 & 38 & 92 & 2.34 & 0.03 & 2.53 & 743 & 113 \\
\hline GB1 & 38 & 121 & 2.43 & 0.05 & 2.51 & 809 & 126 \\
\hline GB1 & 38 & 150 & 2.41 & 0.09 & 2.50 & 886 & 151 \\
\hline GB1 & 38 & 175 & 2.57 & 0.05 & 2.50 & 811 & 168 \\
\hline GB1 & 38 & 220 & 2.43 & 0.06 & 2.50 & 911 & 206 \\
\hline GB1 & 38 & 280.2 & 2.47 & 0.05 & 2.48 & 938 & 247 \\
\hline GB1 & 38 & 350.7 & 2.74 & 0.08 & 2.48 & 678 & 265 \\
\hline GB1 & 46 & 10 & 1.40 & 0.02 & 2.43 & 395 & 20 \\
\hline GB1 & 46 & 16.8 & 1.47 & 0.03 & 2.43 & 573 & 23 \\
\hline GB1 & 46 & 23 & 1.54 & 0.03 & 2.43 & 813 & 28 \\
\hline GB1 & 46 & 35.7 & 1.41 & 0.02 & 2.42 & 1,090 & 32 \\
\hline GB1 & 46 & 42.03 & 1.37 & 0.02 & 2.42 & 1,338 & 34 \\
\hline GB1 & 46 & 52.1 & 1.36 & 0.03 & 2.42 & 1,652 & 38 \\
\hline GB1 & 46 & 62.7 & 1.74 & 0.07 & 2.42 & 2,123 & 69 \\
\hline GB1 & 46 & 100.4 & 2.44 & 0.03 & 2.41 & 2,089 & 102 \\
\hline GB1 & 46 & 150.4 & 2.51 & 0.05 & 2.40 & 1,937 & 146 \\
\hline GB1 & 46 & 200.4 & 2.46 & 0.05 & 2.40 & 1,850 & 174 \\
\hline GB1 & 46 & 250.2 & 2.37 & 0.11 & 2.39 & 1,874 & 283 \\
\hline GB1 & 46 & 325.3 & 2.53 & 0.12 & 2.38 & 1,712 & 314 \\
\hline GB1 & 59 & 10.4 & 1.46 & 0.03 & 2.34 & 335 & 21 \\
\hline GB1 & 59 & 16.1 & 1.43 & 0.06 & 2.34 & 493 & 25 \\
\hline GB1 & 59 & 22.5 & 1.64 & 0.21 & 2.34 & 673 & 61 \\
\hline GB1 & 59 & 34 & 1.61 & 0.12 & 2.34 & 857 & 69 \\
\hline GB1 & 59 & 40 & 1.50 & 0.03 & 2.34 & 1,013 & 70 \\
\hline GB1 & 59 & 47 & 1.49 & 0.05 & 2.34 & 1,256 & 73 \\
\hline
\end{tabular}




\begin{tabular}{|c|c|c|c|c|c|c|c|}
\hline GB1 & 59 & 60 & 1.49 & 0.09 & 2.34 & 1,844 & 102 \\
\hline GB1 & 59 & 95 & 2.12 & 0.05 & 2.35 & 2,108 & 128 \\
\hline GB1 & 59 & 140 & 2.05 & 0.06 & 2.36 & 2,509 & 159 \\
\hline GB1 & 59 & 185 & 2.24 & 0.09 & 2.37 & 2,673 & 202 \\
\hline GB1 & 59 & 225 & 2.16 & 0.05 & 2.37 & 3,113 & 244 \\
\hline GB1 & 59 & 325 & 2.34 & 0.04 & 2.40 & 3,189 & 262 \\
\hline GB1 & 70 & 17 & 1.86 & 0.06 & 2.36 & 314 & 47 \\
\hline GB1 & 70 & 27 & 1.85 & 0.06 & 2.36 & 460 & 52 \\
\hline GB1 & 70 & 37 & 1.76 & 0.05 & 2.36 & 721 & 61 \\
\hline GB1 & 70 & 57.5 & 1.81 & 0.06 & 2.36 & 967 & 69 \\
\hline GB1 & 70 & 68 & 1.90 & 0.05 & 2.37 & 1,119 & 72 \\
\hline GB1 & 70 & 80 & 2.05 & 0.05 & 2.37 & 1,266 & 80 \\
\hline GB1 & 70 & 100 & 2.36 & 0.06 & 2.38 & 1,280 & 94 \\
\hline GB1 & 70 & 125 & 2.29 & 0.18 & 2.38 & 1,361 & 190 \\
\hline GB1 & 70 & 160 & 2.35 & 0.06 & 2.39 & 1,412 & 208 \\
\hline GB1 & 70 & 200 & 2.40 & 0.09 & 2.40 & 1,414 & 248 \\
\hline GB1 & 70 & 250 & 2.45 & 0.09 & 2.40 & 1,342 & 286 \\
\hline GB1 & 70 & 300 & 2.27 & 0.06 & 2.41 & 1,439 & 292 \\
\hline GB1 & 77 & 17 & 1.71 & 0.06 & 2.35 & 399 & 45 \\
\hline GB1 & 77 & 26 & 1.68 & 0.05 & 2.35 & 573 & 49 \\
\hline GB1 & 77 & 35 & 1.84 & 0.05 & 2.35 & 794 & 57 \\
\hline GB1 & 77 & 56 & 1.79 & 0.06 & 2.35 & 1,047 & 66 \\
\hline GB1 & 77 & 66 & 1.86 & 0.06 & 2.35 & 1,197 & 70 \\
\hline GB1 & 77 & 77 & 1.97 & 0.06 & 2.36 & 1,391 & 79 \\
\hline GB1 & 77 & 101 & 2.25 & 0.08 & 2.37 & 1,485 & 105 \\
\hline GB1 & 77 & 130 & 2.30 & 0.06 & 2.39 & 1,561 & 122 \\
\hline GB1 & 77 & 160 & 2.31 & 0.06 & 2.39 & 1,630 & 139 \\
\hline GB1 & 77 & 190 & 2.16 & 0.05 & 2.40 & 1,903 & 162 \\
\hline GB1 & 77 & 240 & 2.40 & 0.07 & 2.40 & 1,917 & 213 \\
\hline GB1 & 77 & 300 & 2.40 & 0.13 & 2.41 & 1,922 & 243 \\
\hline GB1 & 85 & 12.6 & 1.30 & 0.05 & 2.35 & 476 & 32 \\
\hline GB1 & 85 & 19 & 1.55 & 0.07 & 2.35 & 629 & 35 \\
\hline GB1 & 85 & 26 & 1.41 & 0.06 & 2.35 & 925 & 43 \\
\hline GB1 & 85 & 41 & 1.52 & 0.07 & 2.35 & 1,197 & 52 \\
\hline GB1 & 85 & 49 & 1.76 & 0.07 & 2.35 & 1,340 & 56 \\
\hline GB1 & 85 & 58 & 1.91 & 0.07 & 2.35 & 1,493 & 63 \\
\hline GB1 & 85 & 73 & 1.86 & 0.08 & 2.35 & 1,858 & 94 \\
\hline GB1 & 85 & 110 & 2.17 & 0.09 & 2.36 & 2,034 & 133 \\
\hline GB1 & 85 & 140 & 2.34 & 0.09 & 2.36 & 2,059 & 168 \\
\hline GB1 & 85 & 180 & 2.36 & 0.09 & 2.37 & 2,076 & 207 \\
\hline GB1 & 85 & 220 & 2.46 & 0.09 & 2.38 & 1,931 & 273 \\
\hline GB1 & 85 & 300 & 2.60 & 0.10 & 2.39 & 1,683 & 300 \\
\hline GB1 & 92 & 10 & 1.68 & 0.07 & 2.34 & 239 & 32 \\
\hline
\end{tabular}




\begin{tabular}{|c|c|c|c|c|c|c|c|}
\hline GB1 & 92 & 15 & 1.61 & 0.07 & 2.34 & 365 & 35 \\
\hline GB1 & 92 & 22 & 1.54 & 0.07 & 2.34 & 571 & 41 \\
\hline GB1 & 92 & 33 & 1.78 & 0.04 & 2.34 & 709 & 43 \\
\hline GB1 & 92 & 39 & 1.65 & 0.05 & 2.34 & 837 & 45 \\
\hline GB1 & 92 & 46 & 1.59 & 0.04 & 2.34 & 1,053 & 48 \\
\hline GB1 & 92 & 59 & 1.59 & 0.06 & 2.34 & 1,639 & 77 \\
\hline GB1 & 92 & 100 & 2.65 & 0.07 & 2.35 & 1,332 & 117 \\
\hline GB1 & 92 & 130 & 2.28 & 0.06 & 2.36 & 1,396 & 134 \\
\hline GB1 & 92 & 160 & 2.41 & 0.09 & 2.36 & 1,339 & 170 \\
\hline GB1 & 92 & 200 & 2.42 & 0.06 & 2.37 & 1,248 & 232 \\
\hline GB1 & 92 & 302 & 2.29 & 0.06 & 2.38 & 1,391 & 259 \\
\hline GB1 & 101 & 13.6 & 1.57 & 0.04 & 2.36 & 405 & 33 \\
\hline GB1 & 101 & 22 & 1.46 & 0.04 & 2.36 & 611 & 35 \\
\hline GB1 & 101 & 29.5 & 1.58 & 0.05 & 2.36 & 867 & 42 \\
\hline GB1 & 101 & 45 & 1.61 & 0.05 & 2.36 & 1,133 & 49 \\
\hline GB1 & 101 & 54 & 1.74 & 0.06 & 2.37 & 1,296 & 52 \\
\hline GB1 & 101 & 63 & 1.89 & 0.06 & 2.37 & 1,484 & 61 \\
\hline GB1 & 101 & 81 & 1.96 & 0.07 & 2.37 & 1,763 & 82 \\
\hline GB1 & 101 & 110 & 2.24 & 0.07 & 2.38 & 1,878 & 107 \\
\hline GB1 & 101 & 140 & 2.43 & 0.05 & 2.37 & 1,826 & 122 \\
\hline GB1 & 101 & 171 & 2.43 & 0.05 & 2.37 & 1,774 & 135 \\
\hline GB1 & 101 & 200 & 2.44 & 0.05 & 2.37 & 1,641 & 184 \\
\hline GB1 & 101 & 300 & 2.20 & 0.04 & 2.37 & 1,883 & 205 \\
\hline GB1 & 109 & 11.1 & 1.58 & 0.03 & 2.39 & 318 & 23 \\
\hline GB1 & 109 & 16.2 & 1.69 & 0.04 & 2.39 & 445 & 25 \\
\hline GB1 & 109 & 23.7 & 1.62 & 0.04 & 2.39 & 672 & 31 \\
\hline GB1 & 109 & 36.5 & 1.77 & 0.04 & 2.40 & 854 & 35 \\
\hline GB1 & 109 & 44 & 1.76 & 0.04 & 2.48 & 1,158 & 44 \\
\hline GB1 & 109 & 66 & 2.03 & 0.04 & 2.40 & 1,326 & 53 \\
\hline GB1 & 109 & 76 & 1.99 & 0.04 & 2.40 & 1,524 & 61 \\
\hline GB1 & 109 & 100 & 2.17 & 0.04 & 2.39 & 1,648 & 71 \\
\hline GB1 & 109 & 115 & 2.19 & 0.04 & 2.40 & 1,737 & 76 \\
\hline GB1 & 109 & 130 & 2.43 & 0.05 & 2.40 & 1,722 & 83 \\
\hline GB1 & 109 & 150 & 2.40 & 0.05 & 2.40 & 1,719 & 94 \\
\hline GB1 & 109 & 175 & 2.40 & 0.05 & 2.40 & 1,719 & 97 \\
\hline GB1 & 117 & 10.5 & 1.80 & 0.04 & 2.43 & 243 & 24 \\
\hline GB1 & 117 & 16.3 & 1.69 & 0.03 & 2.43 & 377 & 26 \\
\hline GB1 & 117 & 23 & 1.99 & 0.04 & 2.43 & 484 & 30 \\
\hline GB1 & 117 & 33 & 1.77 & 0.04 & 2.41 & 659 & 34 \\
\hline GB1 & 117 & 42 & 1.95 & 0.04 & 2.41 & 758 & 37 \\
\hline GB1 & 117 & 48 & 1.86 & 0.04 & 2.42 & 918 & 41 \\
\hline GB1 & 117 & 62 & 1.87 & 0.04 & 2.43 & 1,177 & 50 \\
\hline GB1 & 117 & 80 & 2.08 & 0.04 & 2.44 & 1,346 & 58 \\
\hline
\end{tabular}




\begin{tabular}{|c|c|c|c|c|c|c|c|}
\hline GB1 & 117 & 95 & 2.31 & 0.05 & 2.44 & 1,404 & 65 \\
\hline GB1 & 117 & 110 & 2.46 & 0.05 & 2.44 & 1,394 & 71 \\
\hline GB1 & 117 & 125 & 2.61 & 0.05 & 2.43 & 1,290 & 82 \\
\hline GB1 & 117 & 150 & 2.52 & 0.05 & 2.43 & 1,258 & 86 \\
\hline GB2 & 5 & 20 & 1.37 & 6.03 & 2.47 & 948 & 5,206 \\
\hline GB2 & 5 & 40 & 1.70 & 0.08 & 2.47 & 1,403 & 5,206 \\
\hline GB2 & 5 & 61 & 1.84 & 0.07 & 2.47 & 1,768 & 5,206 \\
\hline GB2 & 5 & 71 & 1.89 & 0.15 & 2.48 & 2,015 & 5,206 \\
\hline GB2 & 5 & 80 & 2.18 & 0.07 & 2.47 & 1,889 & 5,207 \\
\hline GB2 & 5 & 90 & 2.56 & 0.07 & 2.47 & 1,862 & 5,207 \\
\hline GB2 & 5 & 100 & 2.52 & 0.08 & 2.48 & 1,850 & 5,207 \\
\hline GB2 & 5 & 111 & 2.54 & 0.08 & 2.47 & 1,832 & 5,207 \\
\hline GB2 & 5 & 120 & 2.44 & 0.09 & 2.47 & 1,849 & 5,207 \\
\hline GB2 & 5 & 150 & 2.50 & 0.07 & 2.48 & 1,821 & 5,208 \\
\hline GB2 & 5 & 201 & 2.82 & 0.14 & 2.47 & 1,058 & 5,218 \\
\hline GB2 & 5 & 300 & 2.71 & 0.09 & 2.46 & 695 & 5,220 \\
\hline GB2 & 27 & 20 & 1.70 & 0.04 & 2.34 & 554 & 53 \\
\hline GB2 & 27 & 40 & 1.56 & 0.04 & 2.34 & 1,114 & 69 \\
\hline GB2 & 27 & 70 & 1.68 & 0.06 & 2.34 & 1,637 & 92 \\
\hline GB2 & 27 & 85 & 1.53 & 0.24 & 2.34 & 2,047 & 155 \\
\hline GB2 & 27 & 95 & 1.97 & 0.05 & 2.34 & 1,828 & 159 \\
\hline GB2 & 27 & 105 & 2.20 & 0.06 & 2.35 & 1,869 & 160 \\
\hline GB2 & 27 & 115 & 2.21 & 0.08 & 2.35 & 1,910 & 162 \\
\hline GB2 & 27 & 125 & 2.28 & 0.06 & 2.35 & 1,931 & 164 \\
\hline GB2 & 27 & 135 & 2.27 & 0.05 & 2.35 & 1,972 & 168 \\
\hline GB2 & 27 & 160 & 2.18 & 0.06 & 2.35 & 2,130 & 181 \\
\hline GB2 & 27 & 200 & 2.41 & 0.06 & 2.36 & 2,063 & 205 \\
\hline GB2 & 27 & 250 & 2.69 & 0.08 & 2.36 & 1,826 & 216 \\
\hline GB2 & 36 & 20 & 1.83 & 0.04 & 2.34 & 434 & 55 \\
\hline GB2 & 36 & 40 & 1.86 & 0.06 & 2.34 & 639 & 65 \\
\hline GB2 & 36 & 50 & 1.82 & 0.08 & 2.34 & 824 & 73 \\
\hline GB2 & 36 & 65 & 1.91 & 0.05 & 2.34 & 981 & 77 \\
\hline GB2 & 36 & 75 & 2.19 & 0.08 & 2.35 & 1,035 & 84 \\
\hline GB2 & 36 & 90 & 2.48 & 0.06 & 2.35 & 988 & 89 \\
\hline GB2 & 36 & 100 & 2.29 & 0.08 & 2.35 & 1,034 & 117 \\
\hline GB2 & 36 & 125 & 2.04 & 0.07 & 2.35 & 1,372 & 148 \\
\hline GB2 & 36 & 150 & 2.23 & 0.06 & 2.35 & 1,161 & 169 \\
\hline GB2 & 36 & 175 & 2.42 & 0.06 & 2.35 & 1,110 & 178 \\
\hline GB2 & 36 & 200 & 2.39 & 0.05 & 2.36 & 1,077 & 194 \\
\hline GB2 & 36 & 250 & 2.58 & 0.07 & 2.36 & 923 & 202 \\
\hline GB2 & 43 & 20 & 1.89 & 0.04 & 2.33 & 383 & 55 \\
\hline GB2 & 43 & 40 & 1.90 & 0.08 & 2.33 & 632 & 76 \\
\hline GB2 & 43 & 60 & 1.93 & 0.08 & 2.33 & 896 & 99 \\
\hline
\end{tabular}




\begin{tabular}{|c|c|c|c|c|c|c|c|}
\hline GB2 & 43 & 85 & 2.06 & 0.07 & 2.34 & 1,034 & 108 \\
\hline GB2 & 43 & 95 & 2.03 & 0.05 & 2.34 & 1,147 & 111 \\
\hline GB2 & 43 & 110 & 2.17 & 0.24 & 2.34 & 1,221 & 153 \\
\hline GB2 & 43 & 125 & 2.25 & 0.05 & 2.34 & 1,258 & 156 \\
\hline GB2 & 43 & 140 & 2.25 & 0.10 & 2.34 & 1,308 & 169 \\
\hline GB2 & 43 & 165 & 2.45 & 0.06 & 2.34 & 1,233 & 177 \\
\hline GB2 & 43 & 190 & 2.35 & 0.06 & 2.35 & 1,230 & 186 \\
\hline GB2 & 43 & 220 & 2.33 & 0.07 & 2.35 & 1,247 & 200 \\
\hline GB2 & 43 & 250 & 2.68 & 0.09 & 2.36 & 1,108 & 205 \\
\hline GB2 & 53 & 20 & 1.87 & 0.08 & 2.34 & 407 & 80 \\
\hline GB2 & 53 & 40 & 1.88 & 0.14 & 2.34 & 668 & 117 \\
\hline GB2 & 53 & 60 & 1.99 & 0.05 & 2.34 & 915 & 126 \\
\hline GB2 & 53 & 90 & 1.98 & 0.05 & 2.34 & 1,120 & 132 \\
\hline GB2 & 53 & 100 & 2.27 & 0.08 & 2.34 & 1,139 & 134 \\
\hline GB2 & 53 & 110 & 2.45 & 0.06 & 2.34 & 1,109 & 136 \\
\hline GB2 & 53 & 120 & 2.40 & 0.06 & 2.34 & 1,056 & 151 \\
\hline GB2 & 53 & 170 & 2.38 & 0.11 & 2.35 & 1,013 & 220 \\
\hline GB2 & 53 & 210 & 2.52 & 0.06 & 2.35 & 827 & 237 \\
\hline GB2 & 53 & 250 & 2.30 & 0.06 & 2.36 & 860 & 241 \\
\hline GB2 & 63 & 20 & 1.88 & 0.09 & 2.34 & 394 & 88 \\
\hline GB2 & 63 & 40 & 1.94 & 0.08 & 2.34 & 625 & 102 \\
\hline GB2 & 63 & 60 & 1.95 & 0.08 & 2.34 & 848 & 115 \\
\hline GB2 & 63 & 80 & 1.92 & 0.05 & 2.34 & 1,089 & 121 \\
\hline GB2 & 63 & 100 & 2.12 & 0.13 & 2.34 & 1,187 & 135 \\
\hline GB2 & 63 & 110 & 2.20 & 0.08 & 2.34 & 1,229 & 138 \\
\hline GB2 & 63 & 120 & 2.25 & 0.10 & 2.34 & 1,285 & 151 \\
\hline GB2 & 63 & 130 & 2.31 & 0.10 & 2.34 & 1,316 & 174 \\
\hline GB2 & 63 & 150 & 2.37 & 0.09 & 2.35 & 1,267 & 191 \\
\hline GB2 & 63 & 175 & 2.38 & 0.09 & 2.35 & 1,248 & 204 \\
\hline GB2 & 63 & 200 & 2.32 & 0.14 & 2.36 & 1,292 & 262 \\
\hline GB2 & 63 & 250 & 2.50 & 0.09 & 2.37 & 1,198 & 272 \\
\hline GB2 & 73 & 20 & 1.80 & 0.06 & 2.35 & 433 & 63 \\
\hline GB2 & 73 & 35 & 1.79 & 0.06 & 2.35 & 675 & 71 \\
\hline GB2 & 73 & 50 & 1.94 & 0.09 & 2.35 & 823 & 79 \\
\hline GB2 & 73 & 60 & 1.96 & 0.07 & 2.35 & 966 & 85 \\
\hline GB2 & 73 & 75 & 2.30 & 0.11 & 2.37 & 997 & 99 \\
\hline GB2 & 73 & 90 & 2.43 & 0.09 & 2.38 & 977 & 108 \\
\hline GB2 & 73 & 105 & 2.63 & 0.07 & 2.39 & 822 & 120 \\
\hline GB2 & 73 & 120 & 2.58 & 0.12 & 2.39 & 677 & 156 \\
\hline GB2 & 73 & 135 & 2.43 & 0.06 & 2.40 & 794 & 168 \\
\hline GB2 & 73 & 160 & 2.34 & 0.06 & 2.40 & 853 & 184 \\
\hline GB2 & 73 & 200 & 2.48 & 0.06 & 2.40 & 807 & 189 \\
\hline GB2 & 87 & 20 & 1.93 & 0.07 & 2.35 & 354 & 71 \\
\hline
\end{tabular}




\begin{tabular}{|c|c|c|c|c|c|c|c|}
\hline GB2 & 87 & 40 & 1.92 & 0.05 & 2.35 & 599 & 81 \\
\hline GB2 & 87 & 60 & 1.75 & 0.06 & 2.35 & 939 & 91 \\
\hline GB2 & 87 & 80 & 1.89 & 0.07 & 2.35 & 1,134 & 98 \\
\hline GB2 & 87 & 90 & 1.88 & 0.05 & 2.35 & 1,268 & 100 \\
\hline GB2 & 87 & 100 & 2.28 & 0.08 & 2.35 & 1,290 & 103 \\
\hline GB2 & 87 & 110 & 2.33 & 0.13 & 2.35 & 1,299 & 115 \\
\hline GB2 & 87 & 125 & 2.35 & 0.08 & 2.36 & 1,302 & 121 \\
\hline GB2 & 87 & 140 & 2.36 & 0.08 & 2.36 & 1,297 & 136 \\
\hline GB2 & 87 & 170 & 2.32 & 0.08 & 2.36 & 1,336 & 159 \\
\hline GB2 & 87 & 200 & 2.48 & 0.09 & 2.37 & 1,213 & 196 \\
\hline GB2 & 87 & 250 & 2.55 & 0.08 & 2.38 & 1,088 & 208 \\
\hline GB2 & 93 & 20 & 1.95 & 0.07 & 2.36 & 352 & 71 \\
\hline GB2 & 93 & 40 & 2.04 & 0.09 & 2.36 & 554 & 96 \\
\hline GB2 & 93 & 65 & 2.14 & 0.08 & 2.36 & 710 & 116 \\
\hline GB2 & 93 & 90 & 1.95 & 0.08 & 2.36 & 944 & 127 \\
\hline GB2 & 93 & 105 & 2.01 & 0.08 & 2.36 & 1,071 & 132 \\
\hline GB2 & 93 & 115 & 2.17 & 0.10 & 2.37 & 1,142 & 137 \\
\hline GB2 & 93 & 130 & 2.57 & 0.09 & 2.39 & 1,061 & 144 \\
\hline GB2 & 93 & 145 & 2.44 & 0.08 & 2.39 & 1,033 & 152 \\
\hline GB2 & 93 & 165 & 2.42 & 0.08 & 2.39 & 1,003 & 170 \\
\hline GB2 & 93 & 180 & 2.40 & 0.09 & 2.39 & 992 & 213 \\
\hline GB2 & 93 & 200 & 2.82 & 0.09 & 2.39 & 469 & 249 \\
\hline GB2 & 93 & 250 & 2.61 & 0.09 & 2.38 & 309 & 259 \\
\hline GB2 & 100 & 20 & 1.89 & 0.05 & 2.42 & 464 & 58 \\
\hline GB2 & 100 & 40 & 1.90 & 0.07 & 2.42 & 764 & 75 \\
\hline GB2 & 100 & 60 & 2.06 & 0.07 & 2.42 & 922 & 83 \\
\hline GB2 & 100 & 70 & 1.80 & 0.05 & 2.42 & 1,101 & 85 \\
\hline GB2 & 100 & 80 & 2.27 & 0.08 & 2.43 & 1,145 & 89 \\
\hline GB2 & 100 & 90 & 2.33 & 0.08 & 2.43 & 1,174 & 94 \\
\hline GB2 & 100 & 100 & 2.66 & 0.28 & 2.43 & 1,110 & 124 \\
\hline GB2 & 100 & 110 & 2.43 & 0.08 & 2.43 & 1,112 & 130 \\
\hline GB2 & 100 & 130 & 2.30 & 0.09 & 2.43 & 1,205 & 151 \\
\hline GB2 & 100 & 160 & 2.48 & 0.09 & 2.43 & 1,157 & 182 \\
\hline GB2 & 100 & 200 & 2.47 & 0.08 & 2.43 & 1,132 & 190 \\
\hline GB2 & 106 & 20 & 1.87 & 0.05 & 2.47 & 603 & 68 \\
\hline GB2 & 106 & 50 & 1.77 & 0.05 & 2.47 & 1,005 & 79 \\
\hline GB2 & 106 & 60 & 1.83 & 0.06 & 2.47 & 1,189 & 82 \\
\hline GB2 & 106 & 70 & 2.09 & 0.08 & 2.48 & 1,301 & 86 \\
\hline GB2 & 106 & 80 & 2.17 & 0.08 & 2.48 & 1,413 & 92 \\
\hline GB2 & 106 & 95 & 2.45 & 0.09 & 2.48 & 1,426 & 107 \\
\hline GB2 & 106 & 115 & 2.62 & 0.09 & 2.48 & 1,335 & 126 \\
\hline GB2 & 106 & 140 & 2.50 & 0.06 & 2.48 & 1,320 & 138 \\
\hline GB2 & 106 & 165 & 2.36 & 0.06 & 2.48 & 1,423 & 154 \\
\hline
\end{tabular}




\begin{tabular}{lrrrrrrc} 
GB2 & 106 & 200 & 2.49 & 0.07 & 2.47 & 1,405 & 186 \\
GB2 & 106 & 250 & 2.64 & 0.17 & 2.46 & 1,274 & 226 \\
GB2 & 112 & 10 & 2.11 & 0.08 & 2.42 & 136 & 40 \\
GB2 & 112 & 20 & 2.39 & 0.09 & 2.42 & 149 & 54 \\
GB2 & 112 & 35 & 2.29 & 0.08 & 2.42 & 199 & 65 \\
GB2 & 112 & 45 & 1.91 & 0.07 & 2.43 & 347 & 69 \\
GB2 & 112 & 55 & 1.80 & 0.07 & 2.42 & 526 & 73 \\
GB2 & 112 & 65 & 2.25 & 0.09 & 2.42 & 589 & 82 \\
GB2 & 112 & 80 & 2.20 & 0.08 & 2.43 & 717 & 97 \\
GB2 & 112 & 105 & 2.47 & 0.09 & 2.43 & 682 & 126 \\
GB2 & 112 & 135 & 2.66 & 0.09 & 2.42 & 466 & 160 \\
GB2 & 112 & 170 & 2.63 & 0.09 & 2.42 & 270 & 186 \\
GB2 & 112 & 200 & 2.69 & 0.10 & 2.42 & -39 & 223 \\
GB2 & 112 & 250 & 2.66 & 0.10 & 2.42 & -211 & 237 \\
GB2 & 119 & 10 & 1.73 & 0.19 & 2.42 & 347 & 96 \\
GB2 & 119 & 25 & 1.73 & 0.05 & 2.42 & 644 & 101 \\
GB2 & 119 & 40 & 1.77 & 0.06 & 2.42 & 923 & 106 \\
GB2 & 119 & 55 & 2.00 & 0.07 & 2.42 & 1,072 & 110 \\
GB2 & 119 & 65 & 2.16 & 0.07 & 2.43 & 1,147 & 113 \\
GB2 & 119 & 74 & 2.21 & 0.07 & 2.43 & 1,226 & 117 \\
GB2 & 119 & 90 & 2.43 & 0.08 & 2.43 & 1,223 & 124 \\
GB2 & 119 & 105 & 2.32 & 0.08 & 2.42 & 1,280 & 135 \\
GB2 & 119 & 130 & 2.60 & 0.08 & 2.43 & 1,127 & 158 \\
GB2 & 119 & 165 & 2.69 & 0.09 & 2.42 & 853 & 189 \\
GB2 & 119 & 200 & 2.50 & 0.08 & 2.42 & 756 & 218 \\
GB2 & 119 & 250 & 2.75 & 0.09 & 2.42 & 516 & 231 \\
\hline & & & & & & &
\end{tabular}


Table S2. ${ }^{234} \mathrm{Th}$ and POC fluxes at $\mathrm{z}_{\mathrm{Th} / \mathrm{U}}$, estimated at 27 stations along cruises GB1 and GB2. $\mathrm{z}_{\mathrm{Th} / \mathrm{U}}$ is the depth where ${ }^{234} \mathrm{Th}$ and ${ }^{238} \mathrm{U}$ activities re-establish secular equilibrium. Calculations of POC flux from ${ }^{234} \mathrm{Th}$ fluxes are described in Sect. 2.4. POC flux errors are propagated from ${ }^{234} \mathrm{Th}$ flux, and POC: ${ }^{234} \mathrm{Th}$ errors.

\begin{tabular}{|c|c|c|c|c|c|c|c|}
\hline Cruise & Station & $\mathrm{z}_{\mathrm{Th} / \mathrm{U}}$ & ${ }^{234} \mathrm{Th}$ Flux & ${ }^{234} \mathrm{Th}$ Flux Error & $>51 \mu \mathrm{m}$ POC: $:{ }^{234} \mathrm{Th}$ & POC Flux & POC Flux Error \\
\hline- & - & $m$ & $d p m m^{-2} d^{-1}$ & $d p m m^{-2} d^{-1}$ & $\mu m o l ~ \mathrm{dpm}^{-1}$ & $m m o l ~ m^{-2} d^{-1}$ & $\operatorname{mmol~} m^{-2} d^{-1} 1$ \\
\hline GB1 & 6 & 130 & 2,911 & 121 & 2.0 & 5.7 & 0.25 \\
\hline GB1 & 16 & 140.8 & 2,487 & 139 & 2.6 & 6.6 & 0.37 \\
\hline GB1 & 25 & 115 & 937 & 91 & 1.7 & 1.6 & 0.18 \\
\hline GB1 & 32 & 131 & 1,581 & 186 & 1.3 & 2.0 & 0.20 \\
\hline GB1 & 38 & 121 & 809 & 126 & 2.7 & 2.2 & 0.35 \\
\hline GB1 & 46 & 100 & 2,089 & 102 & 2.8 & 5.9 & 0.32 \\
\hline GB1 & 59 & 95 & 2,108 & 128 & 2.9 & 6.1 & 0.42 \\
\hline GB1 & 70 & 100 & 1,280 & 94 & 4.3 & 5.5 & 0.44 \\
\hline GB1 & 77 & 100 & 1,485 & 105 & 6.0 & 9.0 & 1.3 \\
\hline GB1 & 85 & 140 & 2,059 & 168 & 5.9 & 12 & 1.0 \\
\hline GB1 & 92 & 100 & 1,332 & 117 & 3.8 & 5.1 & 0.47 \\
\hline GB1 & 101 & 140 & 1,826 & 122 & 1.8 & 3.3 & 0.23 \\
\hline GB1 & 109 & 130 & 1,722 & 83 & 1.0 & 1.6 & 0.09 \\
\hline GB1 & 117 & 110 & 1,394 & 71 & 1.0 & 1.4 & 0.09 \\
\hline GB2 & 5 & 90 & 1,862 & 5,207 & 1.3 & 2.5 & 6.9 \\
\hline GB2 & 27 & 105 & 1,869 & 160 & 1.9 & 3.5 & 0.32 \\
\hline GB2 & 36 & 90 & 988 & 89 & 2.0 & 2.0 & 0.18 \\
\hline GB2 & 43 & 125 & 1,258 & 156 & 3.7 & 4.6 & 0.58 \\
\hline GB2 & 53 & 100 & 1,139 & 134 & 3.9 & 4.4 & 0.53 \\
\hline GB2 & 63 & 130 & 1,316 & 174 & 4.6 & 6.1 & 0.81 \\
\hline GB2 & 73 & 75 & 997 & 99 & 4.9 & 4.9 & 0.49 \\
\hline GB2 & 87 & 100 & 1,290 & 103 & 2.9 & 3.8 & 0.33 \\
\hline GB2 & 93 & 130 & 1,061 & 144 & 1.2 & 1.2 & 0.18 \\
\hline GB2 & 100 & 90 & 1,174 & 94 & 2.8 & 3.3 & 0.27 \\
\hline GB2 & 106 & 95 & 1,426 & 107 & 0.9 & 1.2 & 0.10 \\
\hline GB2 & 112 & 105 & 682 & 126 & 0.8 & 0.6 & 0.11 \\
\hline GB2 & 119 & 90 & 1,223 & 124 & 2.5 & 3.0 & 0.31 \\
\hline
\end{tabular}


A
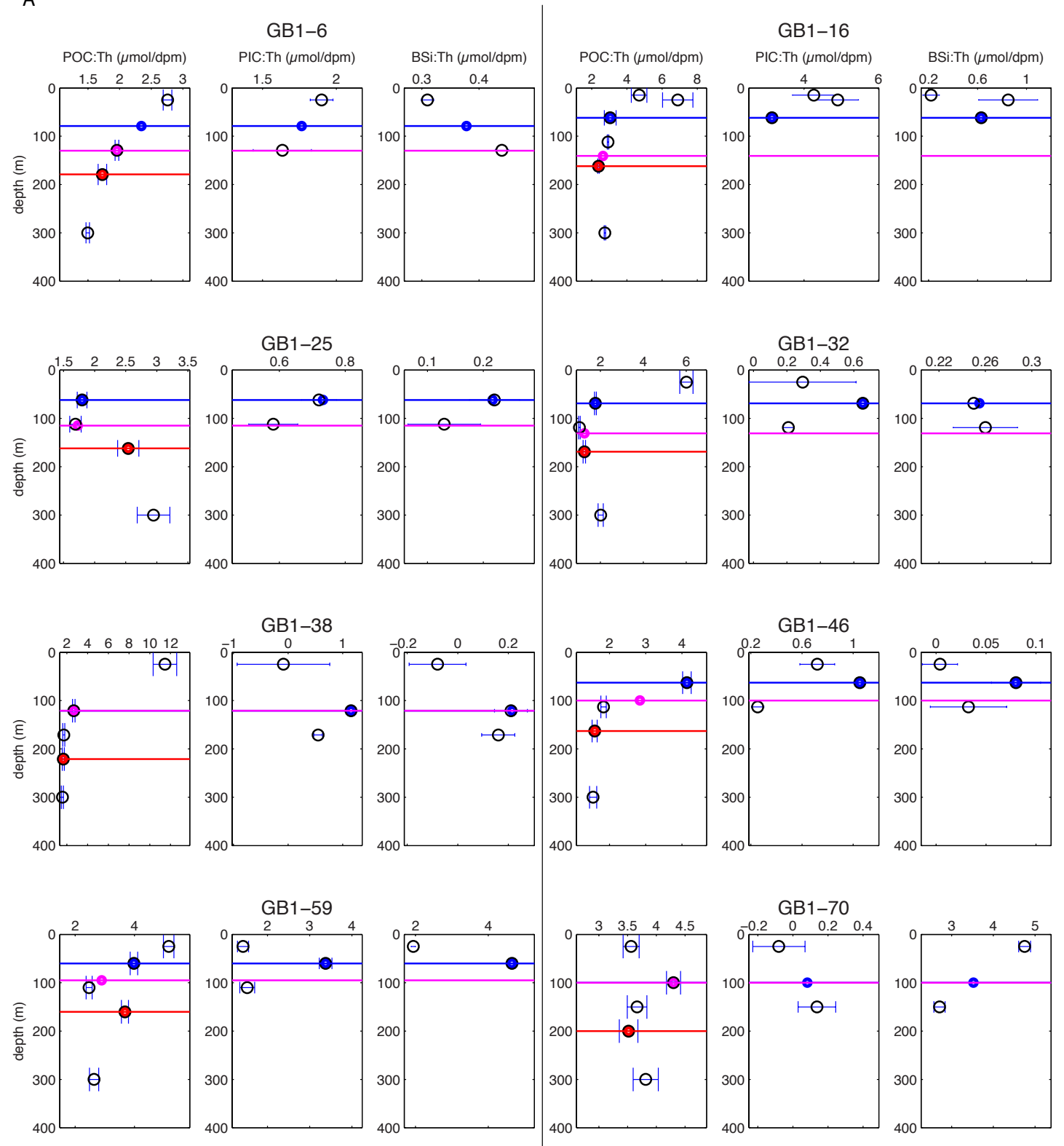

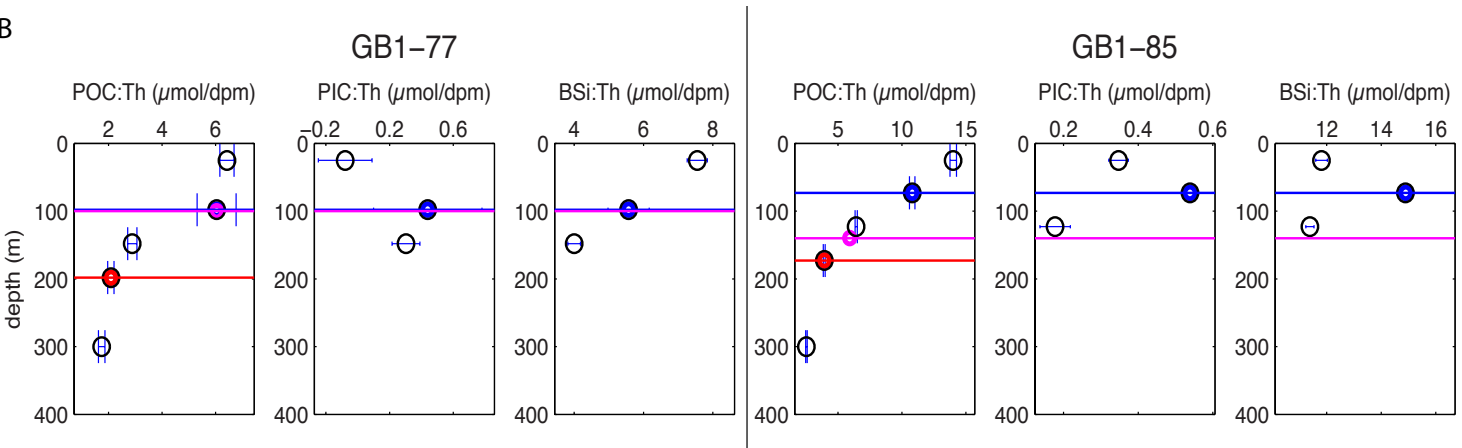

GB1-85

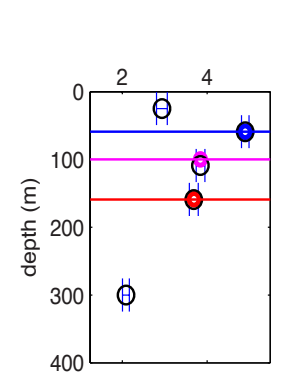

GB1-92
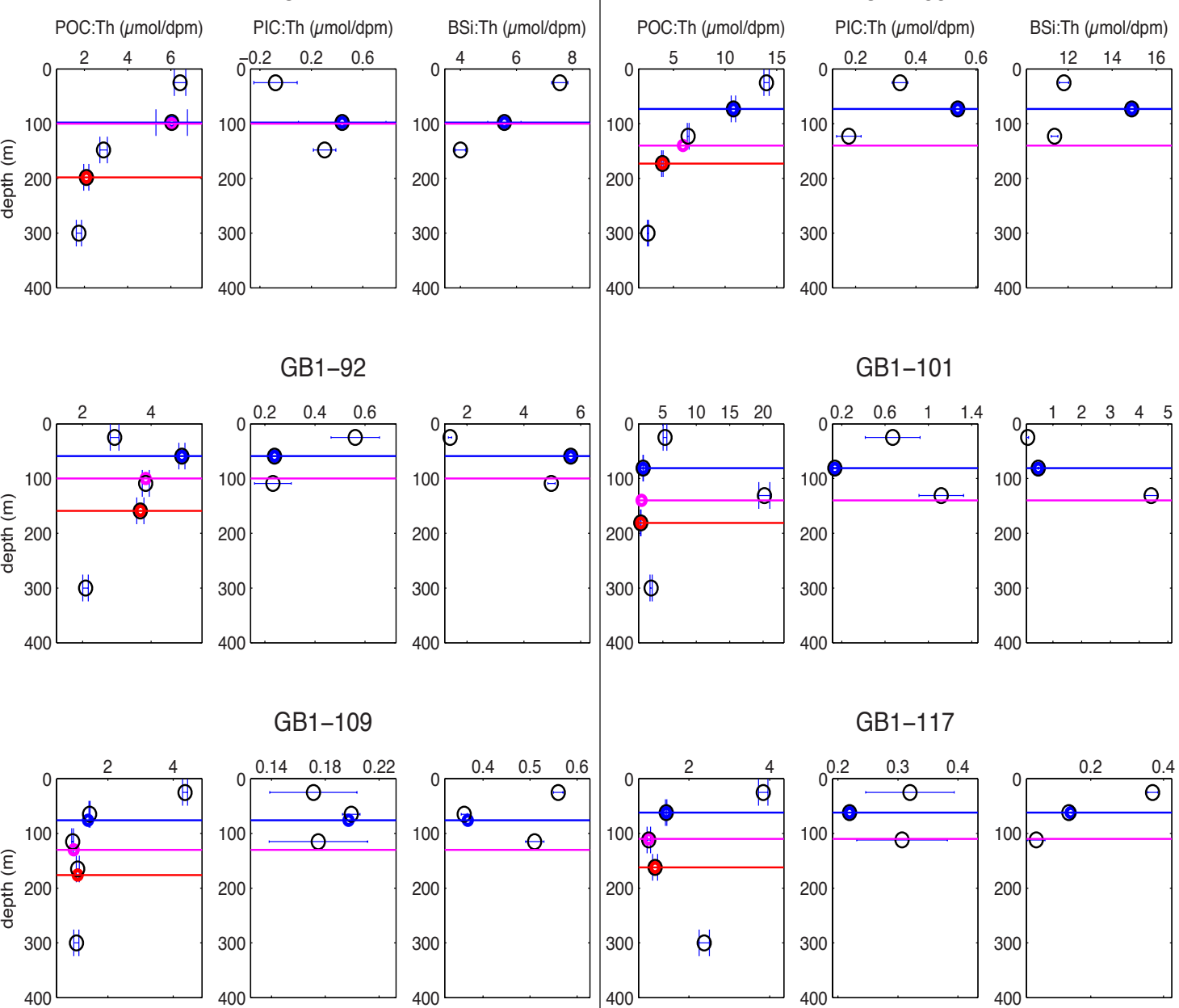

400
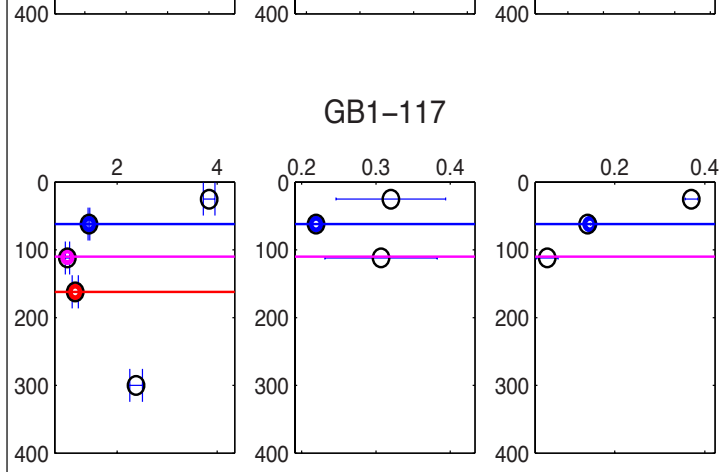

400

400

zPAR

zTh/U

$z P A R+100 m$ 
C
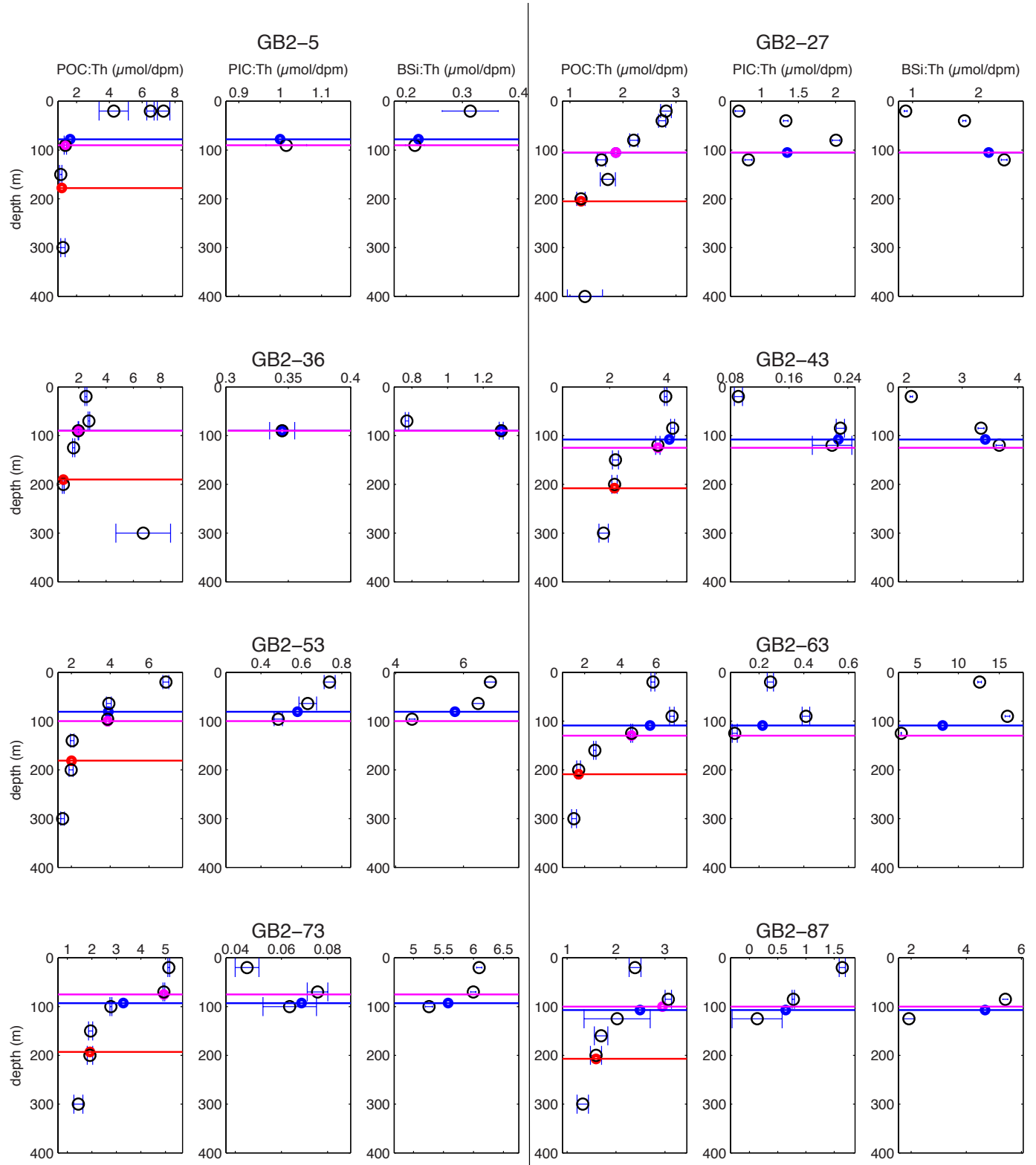
D
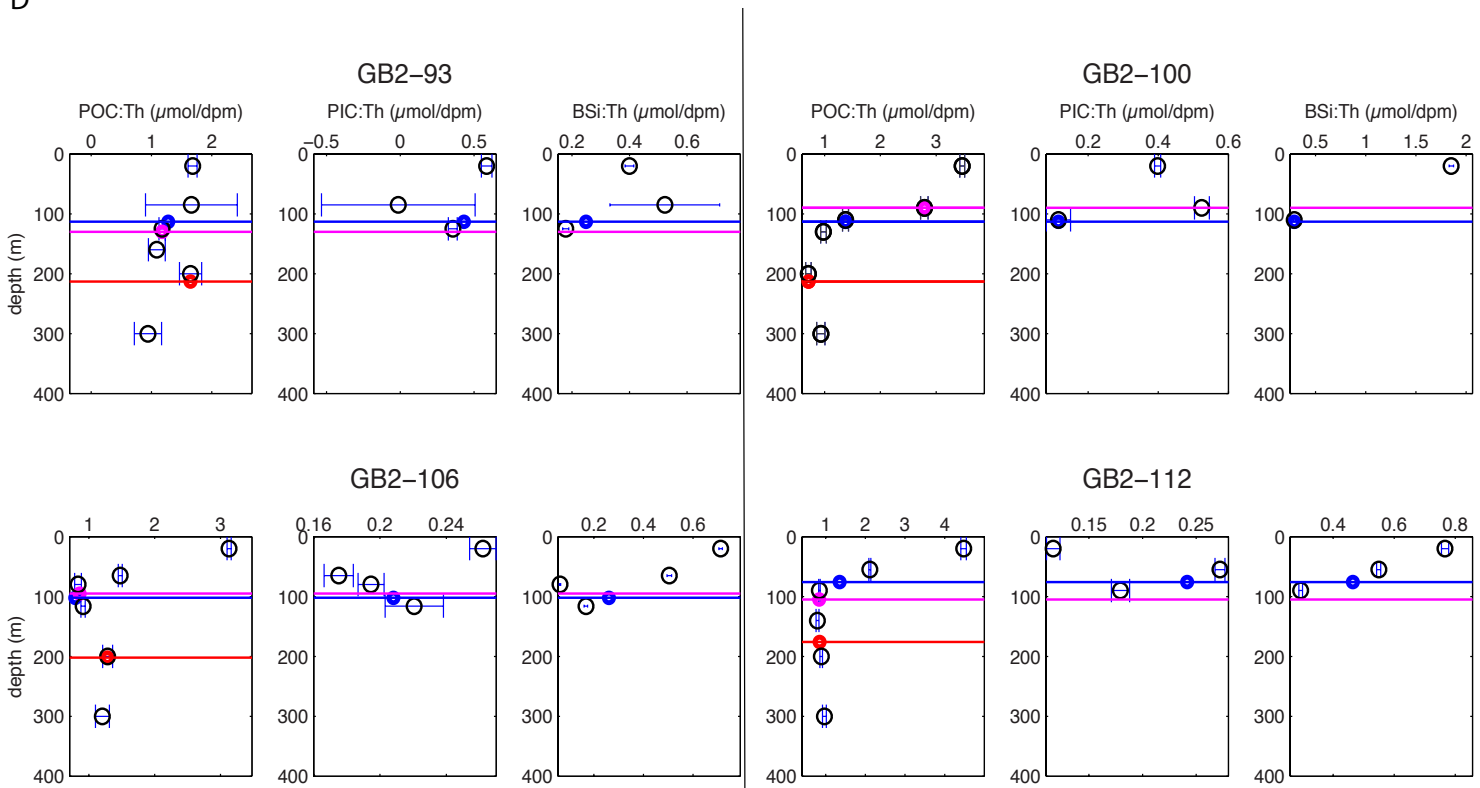

GB2-112

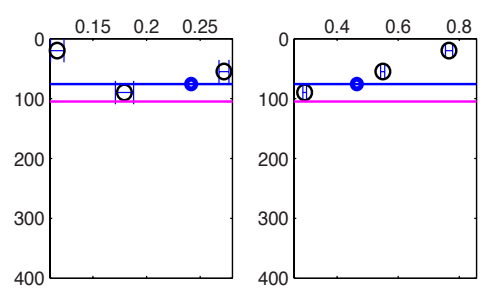

GB2-119
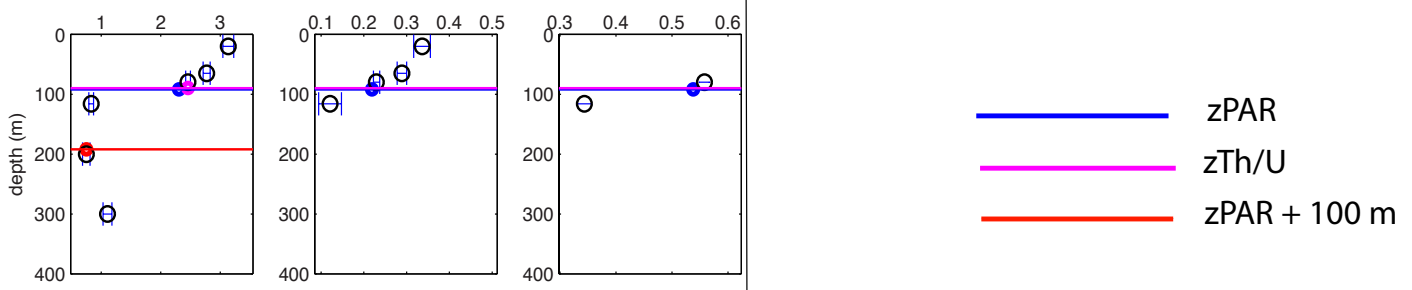

Figure S1. Profiles of $>51 \mu \mathrm{m}$ POC: $: 234$ Th, PIC: $:{ }^{234} \mathrm{Th}$ and BSi: ${ }^{234} \mathrm{Th}$ above $400 \mathrm{~m}$. Black open circles represent measurements. Colored circles represent values at three possible depths (colored lines; see legend) in the POC: ${ }^{234} \mathrm{Th}$ panels, and at ZPAR (blue line) for the PIC: ${ }^{234} \mathrm{Th}$ and $\mathrm{BSi}:{ }^{234} \mathrm{Th}$ panels. These values were interpolated when there were no measurements at these depths (refer to Tables 2 and 3 for specific stations). At station GB2-106, the BSi: ${ }^{234} \mathrm{Th}$ interpolation calculation excluded the anomalously low value at $80 \mathrm{~m}$. Error bars shown are the propagated errors of $>51 \mu \mathrm{m}$ [POC], [PIC], [BSi] and particulate ${ }^{234} \mathrm{Th}$ activity measurements. Note that "negative" values are below the instrument detection limit (see Sect. 2.3), and are equal to 0 within error. 

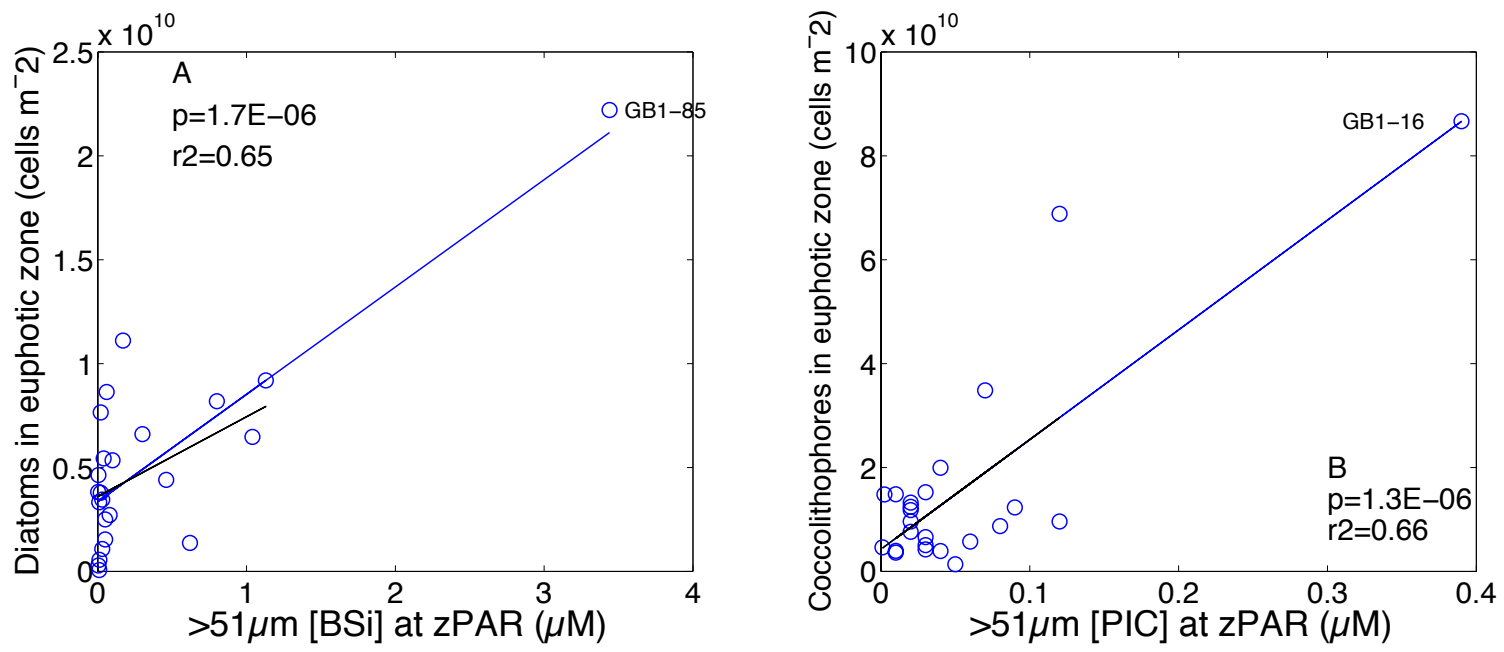

Figure S2. (A) Diatom cell counts integrated from surface to $\mathrm{ZPAR}_{\mathrm{PAR}}\left(\right.$ cells $\mathrm{m}^{-2}$ ) as a function of $>51 \mu \mathrm{m}$ [BSi] at $\mathrm{Z}_{\mathrm{PAR}}$. (B) Integrated coccolithophore cell counts as a function of $>51$ $\mu \mathrm{m}[\mathrm{PIC}]$ at $\mathrm{Z}_{\mathrm{PAR}}$. Outliers for $>51 \mu \mathrm{m}$ [BSi] and [PIC] at stations GB1-85 and GB1-16, respectively, are defined according to Chauvenet's Theorem (Glover et al., 2011). Total euphotic zone cell counts of diatoms and coccolithphores are significantly correlated to $>51 \mu \mathrm{m}[\mathrm{BSi}]$ and [PIC] at $\mathrm{Z}_{\mathrm{PAR}}$, respectively. The significant linear relationships are plotted here as blue lines, with corresponding $\mathrm{p}$ and $\mathrm{r}^{2}$ values indicated. The regressions remain significant $(\mathrm{p}<0.05)$ even when excluding the outliers GB1-85 (Fig. S2a) and GB1-16 (Fig. S2b) from analysis (black lines). We note that cell counts are only available for the $<36 \mu \mathrm{m}$ size-fraction because of the methodology used for enumeration (see Supplemental Methods), while the biomineral measurements are of the $>51 \mu \mathrm{m}$ particle size-fraction (Sect. 2.2). Nonetheless, these relationships suggest that the $>51 \mu \mathrm{m}$ [BSi] and $[\mathrm{PIC}]$ at $\mathrm{Z}_{\mathrm{PAR}}$ do scale with the abundance of diatoms and coccolithophores in the euphotic zone of the water column. 


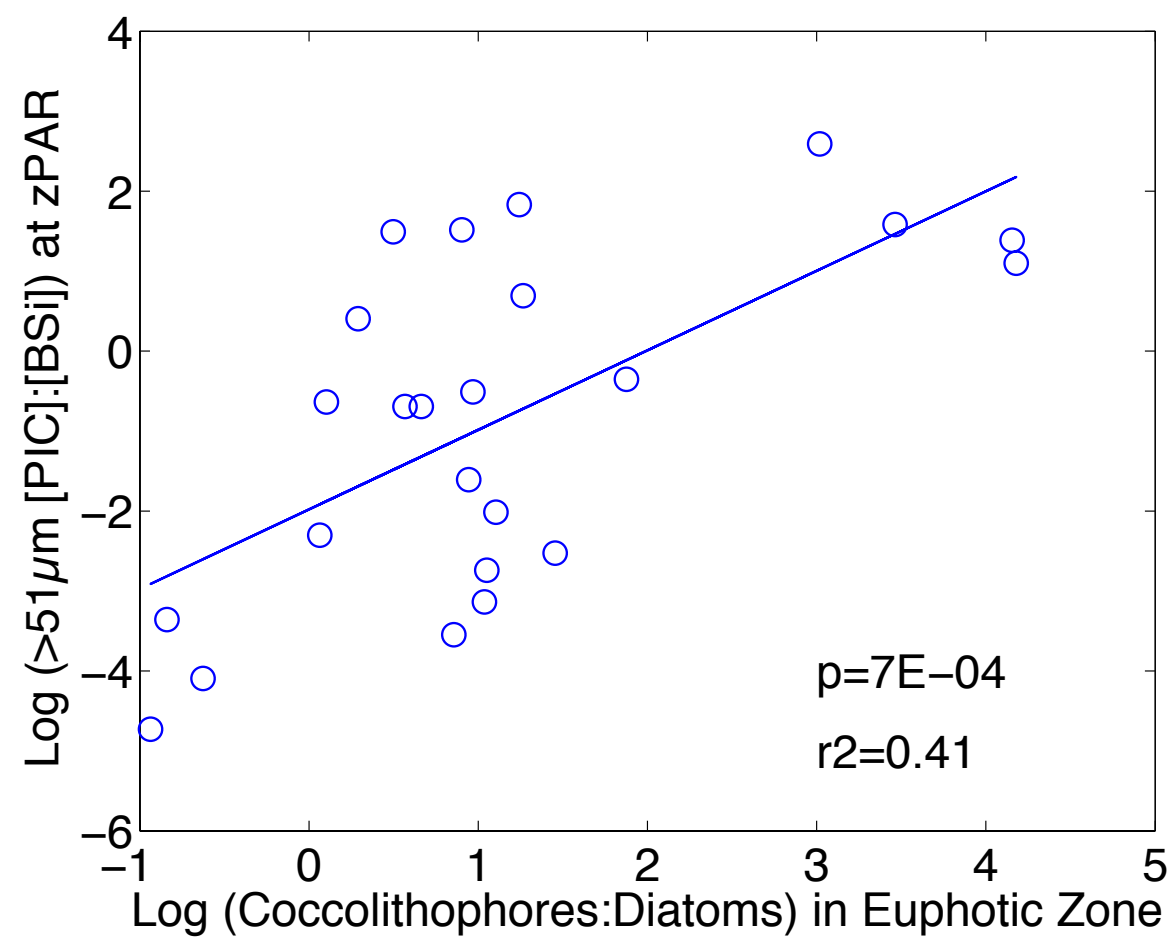

Figure $\mathrm{S} 3$. The natural $\log$ of the ratio of $>51 \mu \mathrm{m}[\mathrm{PIC}]:[\mathrm{BSi}]$ at $\mathrm{Z}_{\mathrm{PAR}}$ as a function of the natural log of the ratio of integrated coccolithophore: diatom cell counts in the euphotic zone. The significant linear relationship is plotted as a blue line, with a corresponding $\mathrm{p}$ and $r^{2}$ value indicated. This further supports the application of $>51 \mu \mathrm{m}$ size-fraction biomineral concentrations at $\mathrm{Z}_{\mathrm{PAR}}$ as a proxy for describing euphotic zone ecosystem composition in Sect. 4.7 and Fig. 10. Despite the different size-fractions that are represented by the biomineral measurements and the cell counts (see Supplemental Methods), the significant correlation nonetheless supports the use of $>51 \mu \mathrm{m}$ biomineral concentration ratios to describe the proportional abundance of certain phytoplankton types. 


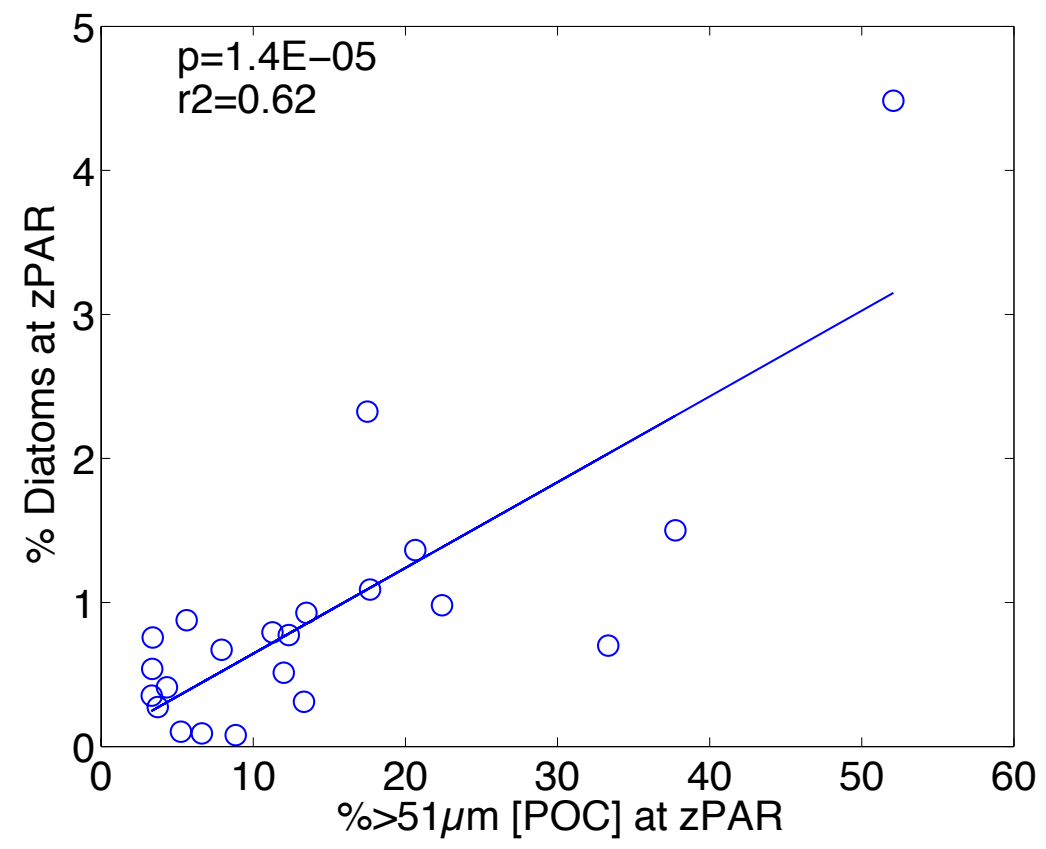

Figure S4. Percentage of total cells that are diatoms at $\mathrm{Z}_{\mathrm{PAR}}$ as a function of the $\%>51$ $\mu \mathrm{m}[\mathrm{POC}]$ at $\mathrm{Z}_{\mathrm{PAR}}$. The significant linear relationship is plotted as a blue line, with a corresponding $\mathrm{p}$ and $\mathrm{r}^{2}$ value indicated. This relationship shows that FlowCAM $\mathbb{R}$ measurements of diatom abundance support our interpretation that the size fractionation of POC $\left(\%>51 \mu \mathrm{m}[\mathrm{POC}]\right.$ at $\left.\mathrm{Z}_{\mathrm{PAR}}\right)$ determined from in-situ pump particle measurements (Sect. 2.2) reflects the relative abundance of diatoms. We note that there is no significant relationship between relative coccolithophore abundance and the size fractionation of POC. 


\section{Supplementary Methods for Figs. S2-S4}

The FlowCAM ${ }^{\circledR}$ imaging cytometer enumerated nano- and microplankton cells from $10 \mathrm{~mL}$ Niskin cast samples at all McLane pump stations except GB2-36, GB2-27 and GB2-119 (refer to Table 1 for station locations) (Poulton and Martin, 2010). Moreover, at stations GB1-38 and GB1-70, cell counts were missing at $\mathrm{Z}_{\mathrm{PAR}}$, and only measured at depths above and below $Z_{P A R}$. The size range of counts was 5.6-35.5 $\mu \mathrm{m}$. While particles $>36 \mu \mathrm{m}$ (up to $200 \mu \mathrm{m}$ ) could be seen in the FlowCAM ${ }^{\circledR}$, they were rare in $10 \mathrm{~mL}$ samples, such that their normalized abundance could not be accurately calculated. Total diatom cell counts in the euphotic zone were approximated by summing FlowCam ${ }^{\circledR}$-derived diatom concentrations (cells $/ \mathrm{mL}$ ) at all depths above $\mathrm{Z}_{\mathrm{PAR}}$ :

$$
\text { total cell counts }=\sum_{1}^{\text {end }} \text { mean }\left[{\frac{\text { cells }}{\mathrm{mL}_{n}}, \frac{\text { cells }}{\mathrm{mL}}}_{n-1}\right] \times\left[z_{n}-z_{n-1}\right]
$$

where $\mathrm{n}$ is the measurement index number from the surface depth at $\mathrm{n}=1$ downward towards $\mathrm{Z}_{\mathrm{PAR}}$ at $\mathrm{n}=$ "end". The unit for this summation is equivalent to cells $\mathrm{m}^{-2}$. Coccoliths and plated cells in the same Niskin samples were counted by birefringence microscopy (Balch et al., 2011). Total coccolithophore counts in the euphotic zone (cells $\mathrm{m}^{-2}$ ) were similarly estimated by summing the microscopy-based concentrations at all depths above ZPAR. 


\section{Supplementary References}

Balch, W. M., Drapeau, D. T., Bowler, B. C., Lyczskowski, E., Booth, E. S., and Alley, D.: The contribution of coccolithophores to the optical and inorganic carbon budgets during the Southern Ocean Gas Exchange Experiment: New evidence in support of the Great Calcite Belt hypothesis, J. Geophys. Res., 116, C00F06, 2011.

Glover, D. M., Jenkins, W. J., and Doney, S. C.: Modeling methods for marine science., Cambridge University Press, 2011.

Poulton, N. J., and Martin, J. L. Imaging flow cytometry for quantitative phytoplankton analysis - FlowCAM. In: Karlson B, Cusack C, Bresnan E (eds) Microscopic and molecular methods for quantitative phytoplankton analysis, Vol Chapter 8. Intergovernmental Oceanographic Commission of UNESCO, Paris, France, 49-54, 2010. 